\title{
Current Harmonics Reduction In Microgrids Using Dual Interfacing Converters
}

\author{
Venkatesh E ${ }^{\text {a }}$, Dr. Mukesh Tiwari ${ }^{\text {b }}$ \\ ${ }^{a}$ Research Scholar, Dept. of Electrical \& Electronics Engineering, \\ Sri Satya Sai University of Technology \& Medical Sciences, Sehore, Bhopal Indore Road, Madhya Pradesh, India \\ ${ }^{\mathbf{b}}$ Research Guide, Dept. of Electrical \& Electronics Engineering, \\ Sri Satya Sai University of Technology \& Medical Sciences, Sehore, Bhopal Indore Road, Madhya Pradesh, India
}

Article History: Received: 11 January 2021; Accepted: 27 February 2021; Published online: 5 April 2021

\begin{abstract}
The Growing Installation of Distributed Generation (DG) units in low voltage conveyance frameworks has promoted the idea of nonlinear load symphonious current remuneration utilizing multi-utilitarian DG interfacing converters. In appropriation frameworks, the load has been an unexpected increment or diminishes and it resembles as nonlinear loads so the load draw non-sinusoidal flows from the AC mains and causes the load sounds and responsive power, and over the top impartial flows that give contamination in power frameworks. It is investigated in this paper that the pay of neighborhood load symphonious current utilizing a solitary DG interfacing converter may make the intensification of supply voltage sounds touchy loads, especially when the primary framework voltage is profoundly twisted. To address this impediment, in contrast to the activity of customary unified power quality conditioners (UPQC) with arrangement converter, another concurrent stock voltage and matrix current symphonious pay technique is proposed utilizing composed control of two shunt interfacing converters. Through the presentation of staggered control destinations, it is delineated that the proposed framework could ride through voltage unsettling influences and proceed with the power move between the nearby generation and the matrix, while an excellent voltage is kept up for the neighborhood loads. By utilizing this proposed regulator, the lattice voltage stage bolted circle and the identification of the load current and the stockpile voltage music are superfluous for both interfacing converters. In this manner, the computational load of interfacing converters can be fundamentally decreased. Mimicked and test results are caught to approve the exhibition of the proposed geography and the control technique.
\end{abstract}

Keywords: Distributed Generation (DG), harmonic current compensation, smart grid.

\section{Introduction}

With the expanding worries on regular energy cost, energy security, and ozone depleting substance discharges, the energy business is encountering essential changes as more distributed-energy-asset based distributed generation (DG) units are being associated with the framework. These DG systems are viewed as a way to encourage the utilization of climate agreeable sustainable power sources. A large portion of these DG systems are associated with the matrix through power electronic interfacing converters. This expanded infiltration of distributed generation presented various difficulties, for example, sounds, assurance obstructions, voltage guideline issues, and so forth Thus, the power quality, just as power guideline necessities, of distributed generation systems is getting more rigid as has just been reflected in a couple of matrix codes. While the distributed generation interfacing converters may bring sounds into the power system and cause power quality concerns, they are likewise ready to improve system proficiency and power quality whenever planned and controlled appropriately. To understand this capacity, other than the main role of genuine power generation, numerous subordinate administrations can likewise be given through distributed generation at whatever point adequate evident power rating is accessible. These subordinate administrations incorporate power factor pay, voltage uphold, gleam alleviation, system consonant remuneration, awkwardness voltage pay and so forth The extra clear power rating is reachable because of the discontinuous idea of many power-gadgets based DG systems, (for example, photovoltaic, wind, and so on) Besides, with the new advancement of savvy lattice and microgrid ideas and the related progression of correspondence, instrumentation, and control strategies for powergadgets interfaced distributed generation, the adaptable control of distributed generation to improve conveyance system power quality.

Power quality issues are related with a broad number of electromagnetic marvels in power systems with expansive scopes of time spans, for example, long length varieties, brief term varieties and different unsettling influences. Brief term varieties are primarily brought about by either flaw conditions or stimulation of enormous loads that require high beginning flows. Contingent upon the electrical distance identified with impedance kind of establishing and association of transformers between the blamed/load area and the hub, there can be a transitory loss of voltage or impermanent voltage decrease (sag) or voltage rise (swell) at various hubs of the system. Power quality is the idea of powering and establishing delicate gear in a matter that is appropriate to the activity of that hardware as per IEEE Std 1100. Different sources utilize the expression "power quality" with various implications. Different sources utilize comparative yet somewhat unique phrasing like "quality of power supply" or "voltage quality".

Need for power quality is:

- Utilities need to convey great item.

- Equipment causes voltage aggravations.

- Equipment has gotten more delicate to voltage unsettling influences. 


\section{Description of the microgridunder Harmonic Conditions}

Figure 2.1 plots the electrical arrangement of a microgrid with inverter-interfaced DGs, diode rectifier and adjusted resistive loads. Three-stage three-legs structure is utilized for inverters and rectifier load. In islanded activity, the inverter interfaced DG are liable for the recurrence and voltage guideline. The diodes rectifier is associated with the organization hub straightforwardly and yields a lot of low-request consonant flows, which break down the power quality of microgrid.

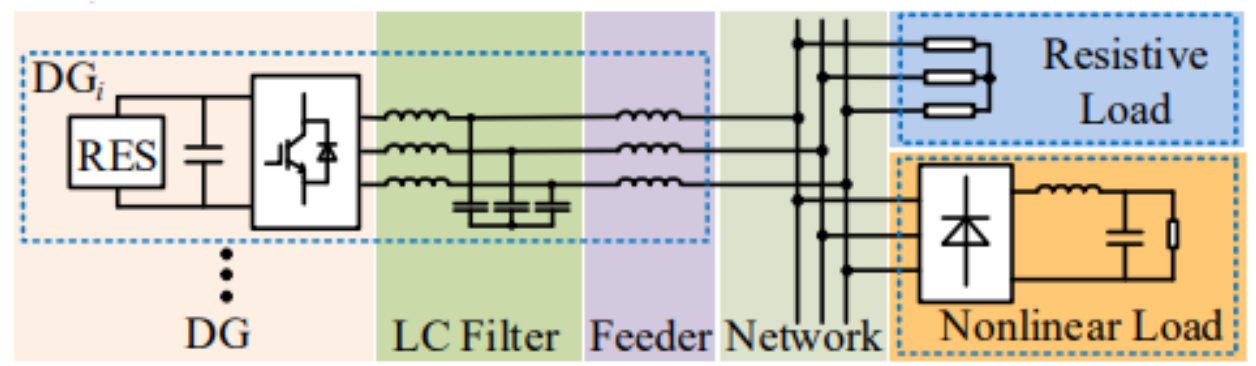

Figure 2.1. Electrical configuration of microgrid

The autonomous power dividing between inverter-interfaced DGs can be accomplished by utilizing hang control method. The square outline of normal hang controlled inverter is introduced in Figure 2.2. Hang regulator controls the rakish recurrence and greatness of reference voltage utilizing the neighborhood estimations. Hang control conspire stays away from the costly high-data transfer capacity correspondence for the power guideline in a versatile microgrid. Notwithstanding, the self-governing voltage control of hang controlled inverter offers ascend to the poor damped control-mode swaying among inverters. The recurrence scope of propositions between inverter swaying generally relies upon the cut-off recurrence of power channel and hang coefficient.

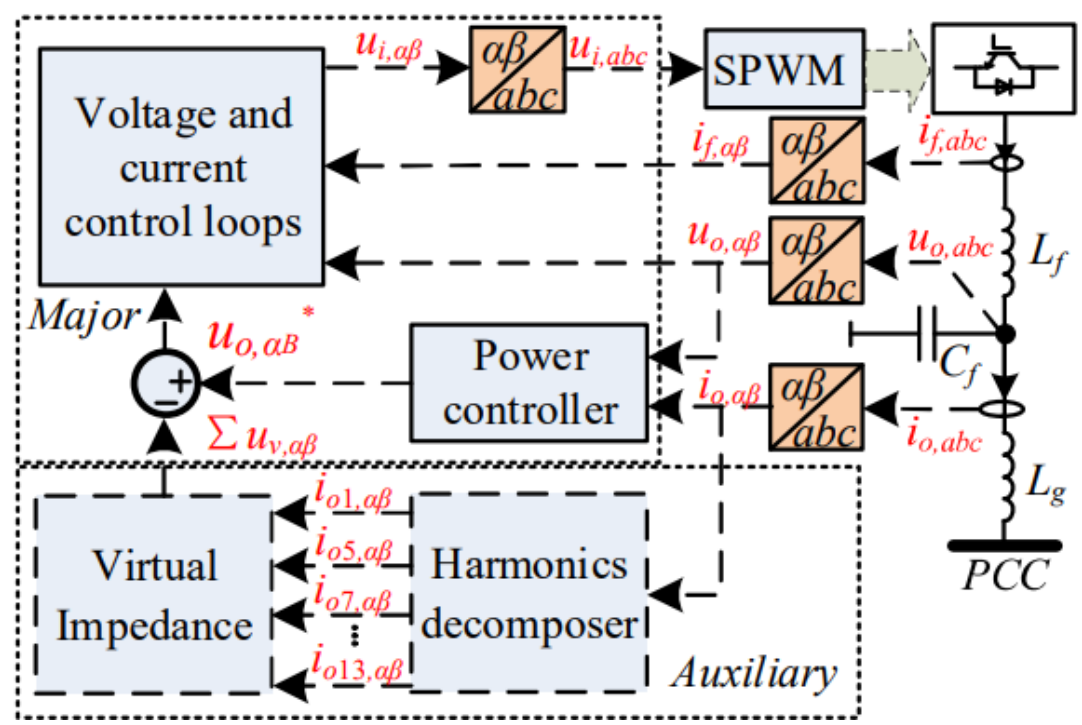

Figure 2.2. Block diagram of current harmonics reduction in microgrids DG

To improve the power guideline of inverter, virtual impedance control is received, where the yield current is utilized as the criticism to make an extra voltage reference. As an assistant regulator, the virtual impedance at fundament recurrence is intended for improving the power sharing, and the virtual impedance at consonant recurrence is applied for symphonious voltage remuneration and symphonious current sharing. The virtual impedance control takes an interest in the voltage control of inverter. The arrangement dynamic channels function as cross breed channel geographies with uninvolved LC channels. In the event that detached LC channels are associated in corresponding to the load then arrangement dynamic power channel works as a symphonious isolator and constraining the load current music to course essentially through the latent channel as opposed to the power dissemination system. The primary preferred position of this geography is that the appraised power of the arrangement dynamic channel is a little part of the load kVA rating.

Nonlinear loads associated with electrical frameworks present voltage and flow twists that influence the standard system activity (with, e.g., capacitors resonances, bogus excursions of circuit) and might be discovered exacerbated in explicit situations like the one of low-voltage (LV) microgrids. To lessen sounds and receptive flow dissemination and conform to electrical codes, uninvolved and dynamic channels have been broadly utilized throughout the long term. These days, with the new decentralization patterns in power systems and the real usage of microgrids, the multifunctional exchanging power interfaces utilized to interface energy assets with the low-voltage network will assume a urgent part in guaranteeing and, conceivably, improving the quality of 
supply. In microgrids, various leveled control approaches demonstrated to be viable in giving dynamic and responsive power control and incorporating these crucial functionalities with further developed ones like distributed symphonious remuneration. Hang control is much of the time embraced in such control structures. The primary test of hang based arrangements is adjusting the compromise between power-sharing precision and matrix voltage sufficiency and recurrence guideline, just as damping the motions of the power traded among sources. To adapt to these angles, in additional hang circles are utilized for symphonious voltage decrease and consonant sharing, while a model prescient control approach is applied to repay voltage unbalances and breaking point over flows.

For what explicitly concerns symphonious remuneration in progressively controlled systems, a two-layer progressive control for coordination of exchanging power interfaces, which depends on a specific resistive/inductive virtual impedance circle at the essential level and a method for voltage consonant bending pay at the auxiliary level; in such a proposition, exchanging power interfaces overloading isn't straightforwardly overseen and voltage symphonious pay requires devoted gadgets like distributed shunt dynamic power channels (APFs). A decentralized versatile control technique for responsive, consonant, and unbalance power sharing, in light of an agreement convention. Another utilizing multi-target booking streamlining to improve the microgrid dynamic and responsive power stream. Other than being actualized through hang control standards, don't depend on the presence of a focal regulator and require correspondence among neighboring specialists. In joins the ideas of variable virtual impedance and feed forward control to accomplish uniform consonant sharing without requiring correspondence, despite the fact that power stream control at PCC isn't thought of the current consonant sharing is accomplished by a hang related pay factor that relies upon the symphonious power accessibility of each exchanging power interfaces. Then again, in view of an open-circle approach, the guideline and power sharing exactnesses are straightforwardly influenced by varieties and non-idealities of system boundaries. Another hang based various leveled approach, which is detailed with an auxiliary layer depending on a correspondence connect, into give dynamic and receptive power sharing.

\section{LITERATURE REVIEW}

Mehdi Savaghebi et al (2020): In this paper, a control approach is proposed for specific pay of primary voltage and current sounds in framework associated microgrids. Two methods of pay are thought of, for example voltage and current pay modes. For the situation that touchy loads are associated with the point of common coupling (PCC), voltage remuneration mode is initiated to give a high voltage quality at PCC. Something else, lattice current sounds are relieved (current remuneration mode) to stay away from exorbitant symphonious stockpile by the matrix. In the two modes, symphonious pay is accomplished through legitimate control of distributed generators (DGs) interface converters. The pay exertion of every consonant is shared considering the comparing current symphonious provided by the DGs. The control system of every DG involves consonant compensator, power regulators, voltage and current regulators and virtual impedance circle. Virtual impedance is considered at major recurrence to upgrade power control and furthermore at consonant frequencies to improve the nonlinear load dividing between DGs. Recreation results are introduced to show the viability of the proposed technique.

Xin Zhao et al (2020): In this paper the creator clarifies about the Unified Voltage Harmonic Control Strategy for Coordinated Compensation. Music have been considered as one of the significant issues in present day power matrices. Considering the high entrance level of power electronic converter interfaced distributed generators (DGs), it is important to offer subordinate types of assistance through DG interfacing converters, for example, consonant remuneration. In the event of that, different DG interfacing converters are used to remunerate music, and the pay exertion ought to be appropriately divided between these converters. Nonetheless, it is seldom viewed as in existing writings that converters working in various modes, for example, voltage-controlled mode (VCM) and current-controlled mode (CCM), need to helpfully give the remuneration work. Focusing on this level headed, this paper proposes a unified voltage consonant alleviation methodology for VCM and CCM converters with high symphonious current sharing precision. Another bit of leeway of the proposition is that matrix side and load-side current estimations are kept away from which diminishes usage cost. Trial results are introduced to exhibit the viability of the strategy. Appropriately, albeit different consonant moderation and current sharing systems have been proposed, a large portion of them experience the ill effects of corrupted voltage quality, restricted sharing precision, or boundary reliance.

\section{PROPOSED METHODOLOGY}

Today, numerous environmentally friendly power based distributed generation (DG) units are associated with the framework with interfacing converters. In this manner, the consonant remuneration capacities can be acknowledged through adaptable control of these converters. With the sounds remuneration capacities, future DG systems could effectively partake in the circulation system power quality control exercises. With the expanding use of nonlinear loads in the conveyance system, power quality issues, particularly music, are turning into a worry in power systems. This is especially obvious in the low-voltage appropriation organization, where electronic gadgets, for example, PCs, reduced fluorescent lights, and numerous other home machines, are 
drawing sounds flows from the framework. These current contortions, compounded with higher feeder impedance in a low-voltage system, could cause impressive voltage mutilations. The voltage sounds are straightforwardly identified with the conveyance system power quality, which may influence delicate loads or even meddle with the correspondence systems nearby the power system framework. Albeit the dissemination system symphonious contortions are not a significant issue today, power quality is crumbling rapidly with the expanding entrance of nonlinear loads. To keep up great power quality, implementing the reception of more severe guidelines on the nonlinear loads is essential. Simultaneously, improvement of a way to remunerate the dissemination system sounds is similarly critical.

There are developing requests of utilizing power molding circuits in low and medium voltage power conveyance system. Contrasting with cumbersome detached channels that are profoundly touchy to circuit boundaries varieties, the dynamic power molding hardware including active power filter (APF), dynamic voltage restorer (DVR), and unified power quality conditioner (UPQC) is liked due the quick unique reaction and the great invulnerability to system boundary changes. Then again, the high infiltration of distributed generation unit with power gadgets interfacing converter offers the chance of power conveyance system symphonious current remuneration utilizing multi-utilitarian DG interfacing converter. To understand an improved dynamic sifting unbiased, the ordinary current control strategies for framework tied DG interfacing converter will be changed. To start with, the wide transfer speed current regulators are utilized so the frequencies of symphonious load current can fall into the transmission capacity of the current regulator. On the other hand, the particular recurrence symphonious pay utilizing multi-thunderous current regulator has gotten a great deal of lessening. The neural organization technique is utilized to improve the consonant sifting execution of DG interfacing converters that are associated with a framework with huge variety of lattice impedance. Notwithstanding the remuneration of music at low voltage conveyance organizations, the dynamic separating of sounds in higher voltage dissemination system utilizing staggered converters. Notwithstanding, it is imperative to take note of that previously mentioned remuneration techniques are fundamentally utilized in matrix tied converter systems. In ongoing writing, the cross breed voltage and current control is likewise evolved to understand a central voltage control for DG power guideline and a symphonious current control for nearby load consonant remuneration. Contrasted with the previously mentioned ordinary current control techniques, the mixture regulator permits an interfacing converter to repay sounds in both matrix tied and islanding micorgrids. With help of the low transmission capacity interchanges between DG units, it likewise conceivable to accomplish symphonious power dividing between equal DG systems.

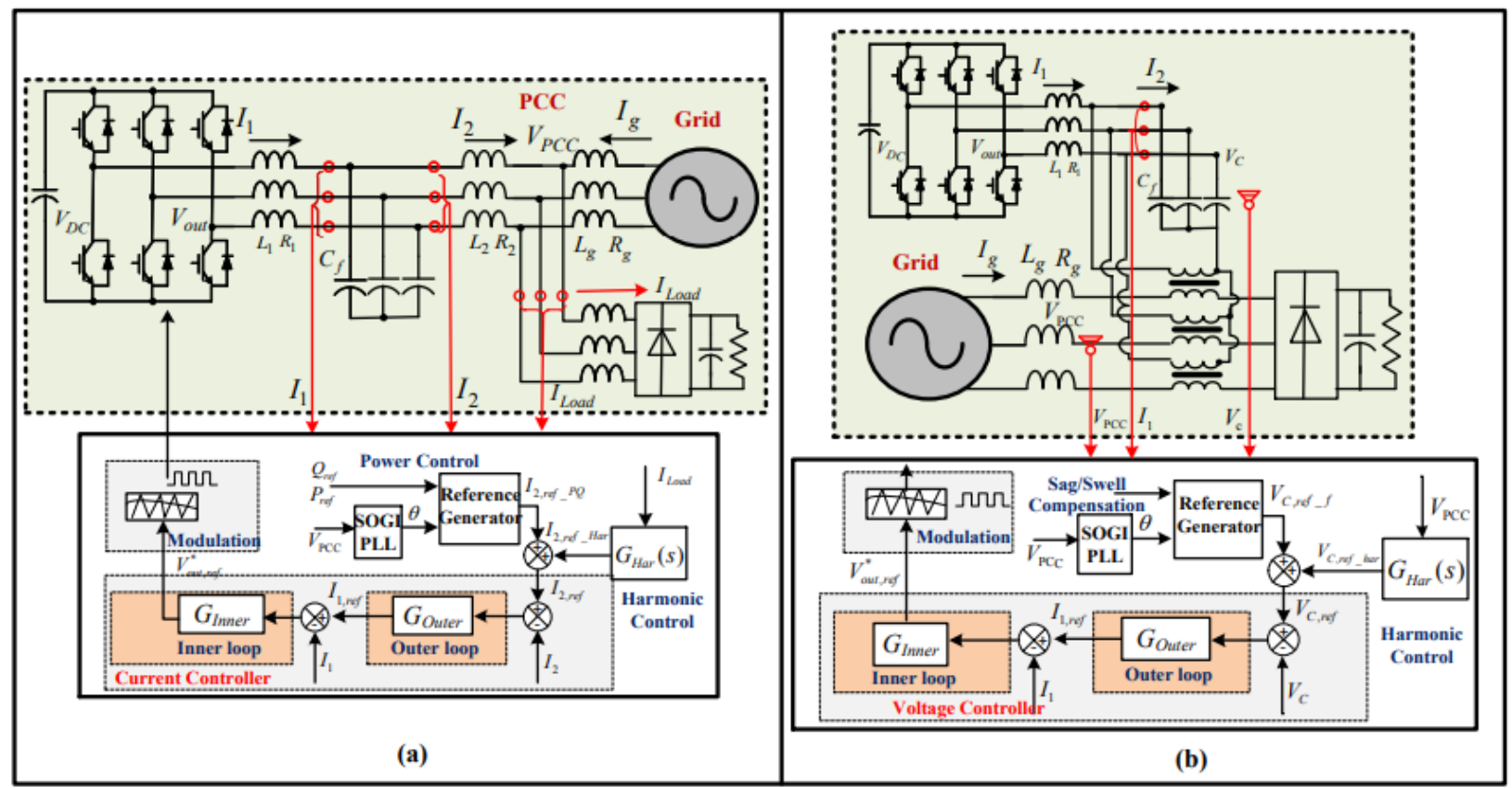

Figure 4.1. Diagram of local harmonic compensation using interfacing converter

Nevertheless, it is critical to accentuation that in any event, when the nearby load consonant current is appropriately remunerated utilizing different regulators as referenced above, great inventory voltage to neighborhood load can't be ensured simultaneously. This issue is especially genuine when the DG interfacing converter is interconnected to a powerless microgrid with nontrivial upstream network voltage contortions. To defeat this restriction, the dynamic voltage restorer (DVR) with arrangement consonant voltage pay ability can be introduced in the power conveyance system. Tragically, the usefulness of an elements voltage restorer can scarcely be actualized in a shunt DG interfacing converter. Utilizing an extra arrangement power molding hardware to guarantee extremely low consistent state consonant inventory voltage to nearby loads is 
unquestionably doable. In any case, it is related with more costs which probably won't be acknowledged for financially cost-effective power conveyance systems.

\section{Proposed System}

An epic made voltage and current regulator for twofold converter system in which the local load is straightforwardly connected with the shunt capacitor of the vital converter. With the setup, the quality of supply voltage can be upgraded through a direct closed circle consonant voltage control of channel capacitor voltage. Meanwhile, the consonant current brought about by the nonlinear load and the principle converter is reimbursed persistently converter.

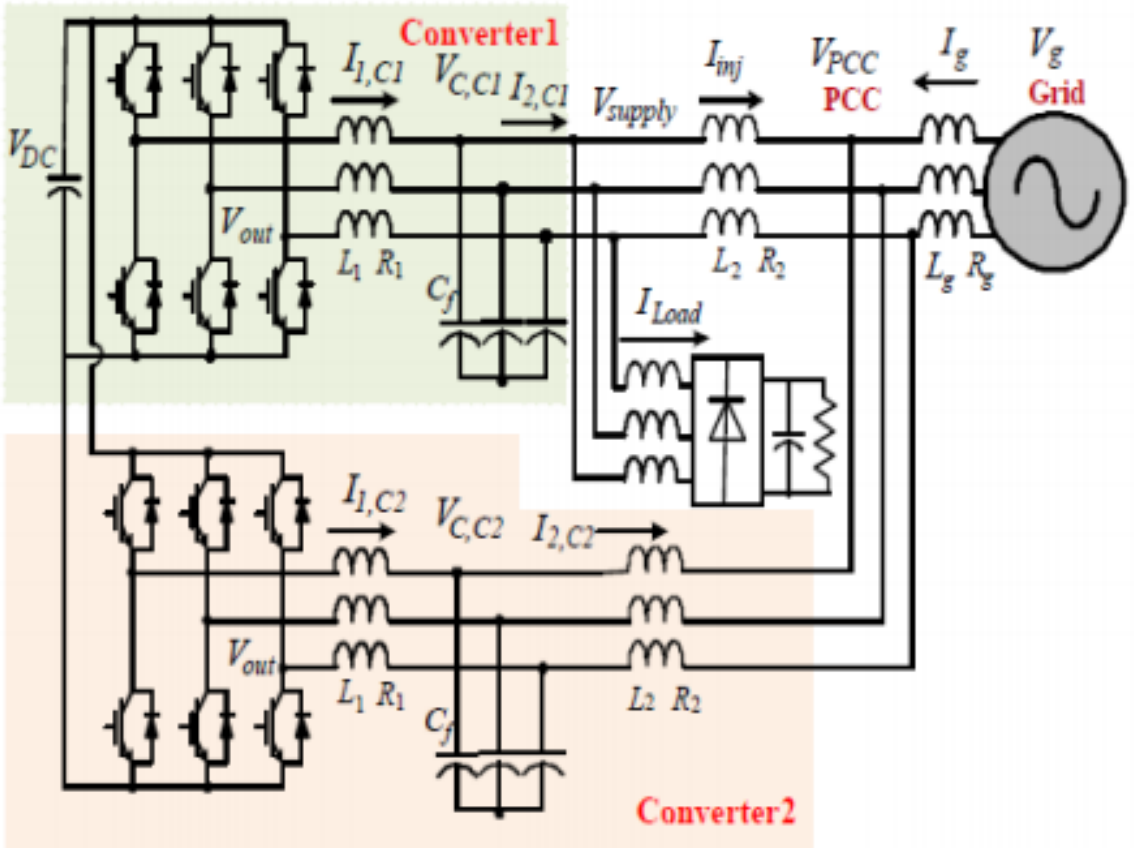

Figure 4.2. Diagram of the interfacing converter topology

Accordingly, the quality of the framework current and the inventory voltage are both generally made progress. To decrease the computational load of dg interfacing converter, the arranged voltage and current control without using load current/supply voltage symphonious extractions or stage jolt circles is made to recognize to encourage control of equal converters. Here develops an equal converter geography where the neighborhood nonlinear load is straightforwardly acquainted with the shunt channel capacitor of the primary converter. The close by load supply voltage quality is improved by the head interfacing converter through consonant voltage control. The harmonic current conveyed by the associations between the close by nonlinear load and the fundamental converter is then reimbursed ceaselessly converter. To decrease the computational load of the twofold converter system, a changed cross breed voltage and current Control strategy is proposed for equal interfacing converters. With accommodating activity of two converters, the load current and supply voltage consonant extraction and the stage catapulted circles are not expected to comprehend this proposed far reaching power quality control objective.

\section{Control Strategy}

The sounds end unit essentially comprises of two significant squares - the music assessment block and the music infusion block. Productive and successful music assessment and sounds disposal strategies are utilized for stage discovery and consonant part assessment. As the presence of the sounds influence the PLL exactness, the principal stage is utilized to wipe out the music from the examined matrix signal guaranteeing precision of the PLL. The subsequent stage gives quick and exact sounds assessment as the PLL produces a precise stage.

The lattice current and the voltage at the PCC are taken care of to the stage bolted look (PLL) block. The PLL block removes the period of the basic part. Then, using the PLL output, the third, fifth harmonics of these signals are estimated. The segments of the assessed sounds are shipped off the music infusion block which chooses how much voltage at the symphonious ought to be infused into the line dependent on the blunder between the genuine and reference. In the sounds infusion unit, the ideal measures of the music are told in the dq reference outline. Wanted THD level is additionally given as a kind of perspective into the regulator block. The THD control block has the instructed THD and the genuine THD of the matrix current or voltage at the PCC. The THD reference is normally set by the necessary power quality. The $\mathrm{d}$ and q part of the symphonious current or voltage ought to be limited to zero to dispense with music from system. The proposed plot guarantees that without a specific sounds, the pay unit doesn't infuse any additional music into the system. The PI regulator is liable for diminishing the symphonious segments beneath as far as possible. At the point when the THD is underneath some reasonable 
cutoff, the PI regulator keeps on inject that specific measure of harmonics which is needed to make the matrix current or the voltage at the PCC harmonics free.

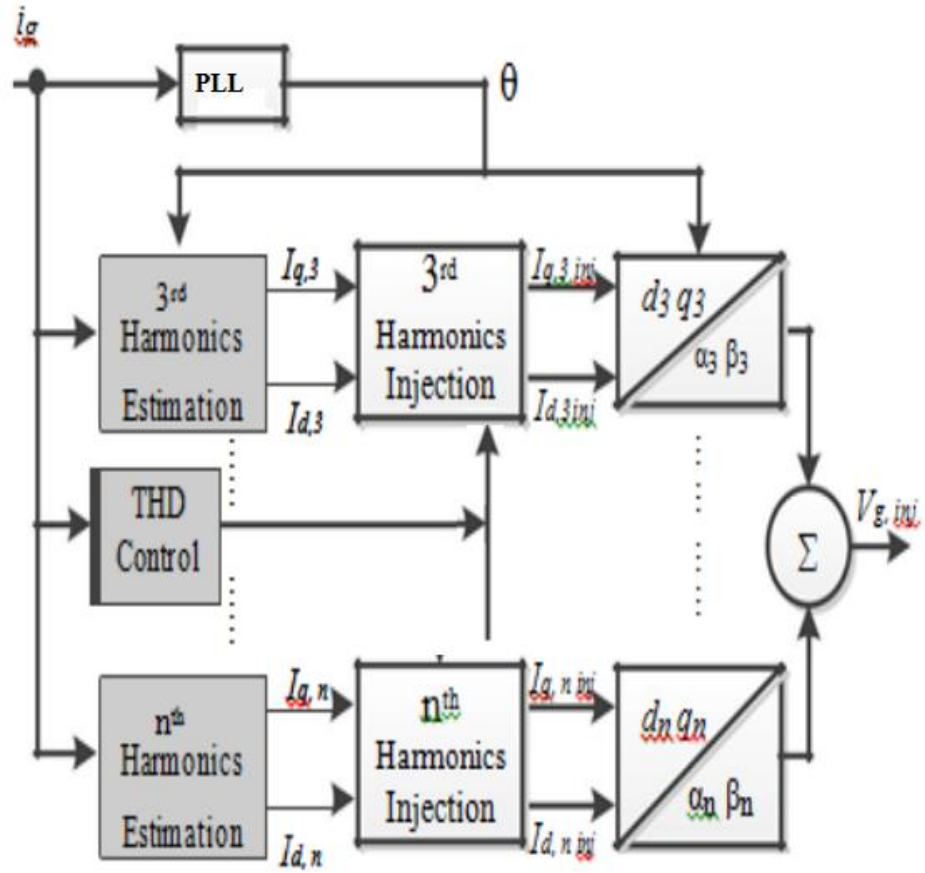

Figure 4.3. Block diagram of control strategy

\section{RESULTS}

The proposed technique is reproduced utilizing MATLAB/SIMULINK software. The Sim Power Systems bundle is utilized for the reenactment of the inverters consolidating the proposed control calculations. The yield voltage waveform before consonant pay and after symphonious remuneration utilizing double interfacing converter is acquired. At first, similar to a solitary interfacing converter is related with the essential framework and the close by nonlinear load is put at the yield terminal of the DG unit. In this multiplication, some steady state consonant contortion is added to the standard matrix voltage and the lattice voltage THD is 5.6\%. At the point when the current regulator is associated with the system, the execution of the system is appeared in figure 5.1. As the local load consonant current is compensated by the DG unit, it might be seen from the second channel of that the lattice current is almost swell free with simply 4.57\% THD. On the other hand, the interfacing converter line current 2 is exceptionally wound for the present circumstance. Standing out from the past reach assessment results in and, it might be clearly seen that the inventory voltage consonant decrease is accomplished to the weakness of more lattice current mutilations. The simultaneous stockpile voltage and framework current sounds control is attempted by using a single DG.

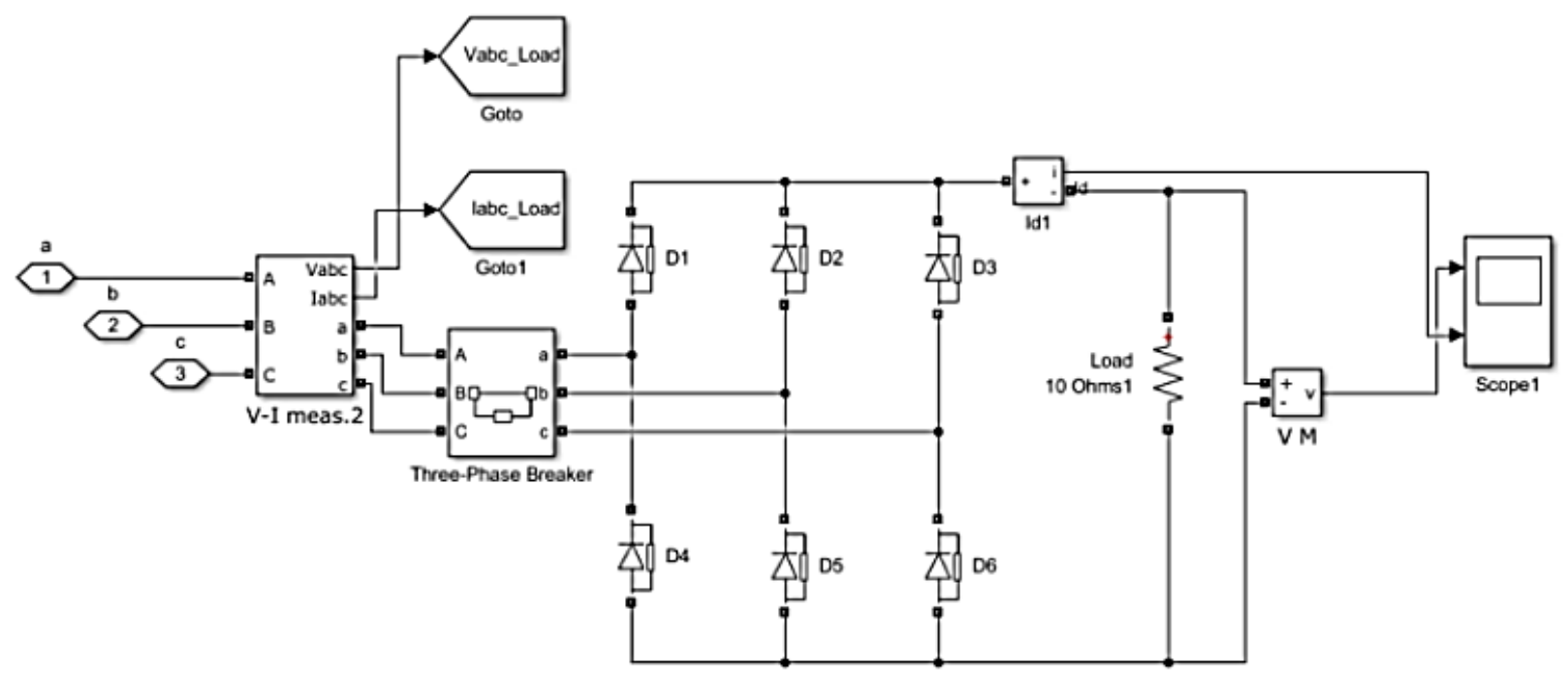

Figure 5.1 Matlab simulation diagram 

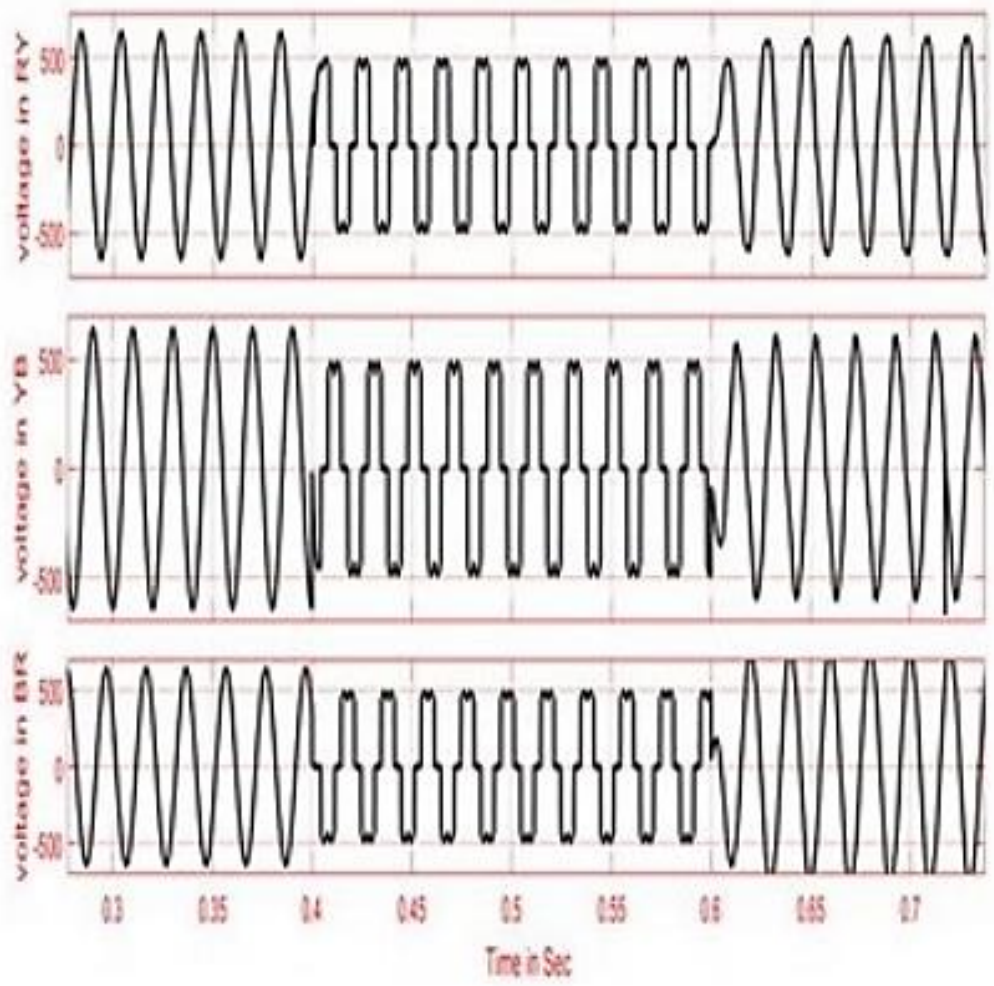

Figure 5.2 Distorted voltage waveform

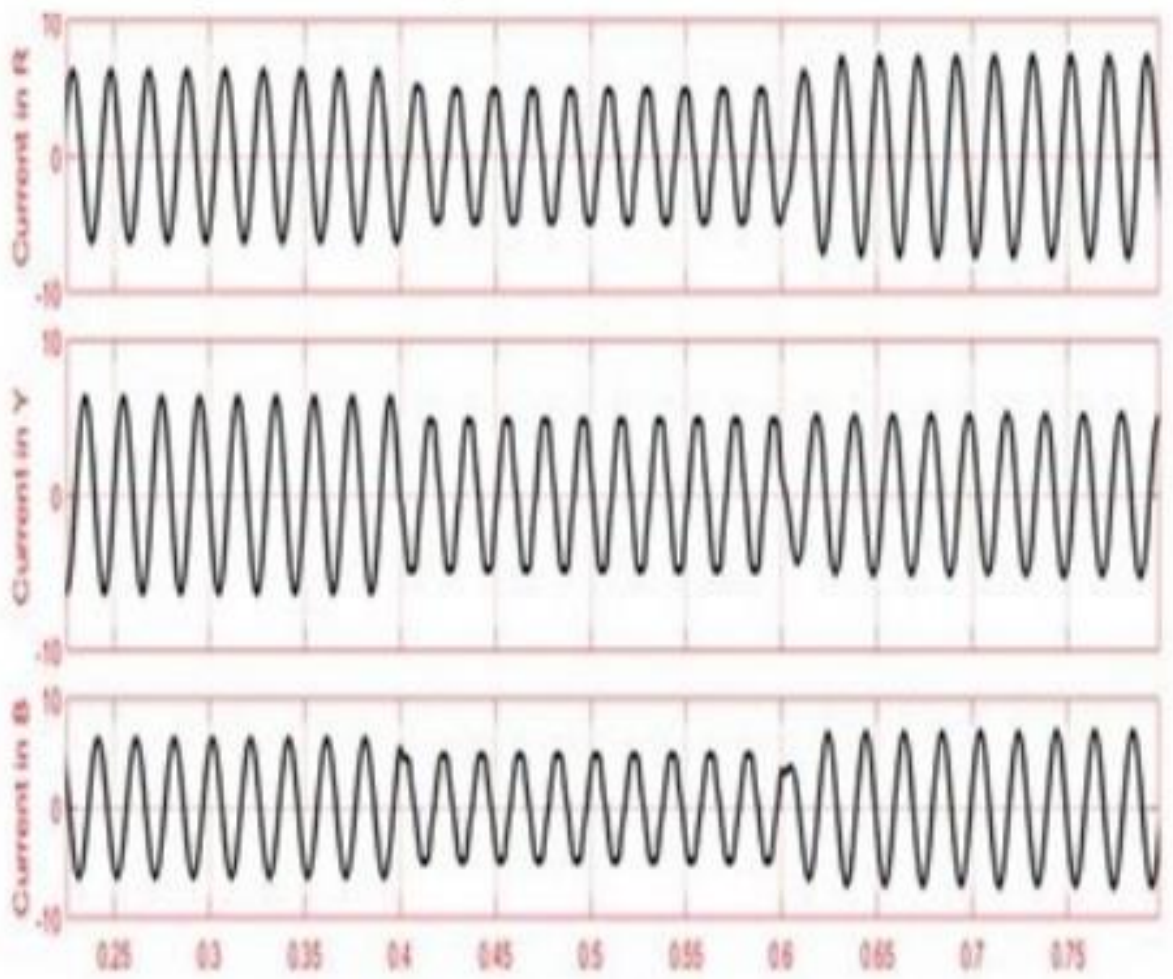

Figure 5.3. Distorted current waveform

\section{CONCLUSION}

A single multi-functional interfacing converter is received to remunerate the consonant current from neighborhood nonlinear loads, the quality of supply voltage to nearby load can barely be improved simultaneously, specific when the principle lattice voltage is contorted. This paper examines a novel facilitated voltage and current regulator for double converter system in which the neighborhood load is straightforwardly associated with the shunt capacitor of the primary converter. With the setup, the quality of supply voltage can be improved by means of a direct shut circle consonant voltage control of channel capacitor voltage. 
Simultaneously, the symphonious current brought about by the nonlinear load and the main converter is remunerated constantly converter. Along these lines, the quality of the matrix current and the stock voltage are both essentially improved. To reduce the computational load of DG interfacing converter, the organized voltage and current control without utilizing load current/supply voltage symphonious extractions or stage lock circles is created to acknowledge to composed control of equal converters.

\section{REFERENCES}

1. Savaghebi, M., Guerrero, J. M., Jalilian, A., \& Vasquez, J. C. (2020). Mitigation of voltage and current harmonics in grid-connected microgrids. 2012 IEEE International Symposium on Industrial Electronics.

2. Zhao, X., Meng, L., Xie, C., Guerrero, J. M., \& Wu, X. (2020). A Unified Voltage Harmonic Control Strategy for Coordinated Compensation With VCM and CCM Converters. IEEE Transactions on Power Electronics, 33(8), 7132-7147. doi:10.1109/tpel.2017.2756688

3. C.Meyer, R.W.DeDoncker, Y.W.Li,andF.Blaabjerg, "Optimized control strategy for a mediumvoltage DVR-Theoretical investigations and experimental results," IEEE Trans.Power Electron.,vol.23,no.6,pp.2746-2754,Nov.2019.

4. S. V. Iyer, M. N. Belur, and M. C. Chandorkar, "A generalized computational method to determine stability of a multi-inverter microgrid," IEEE Trans. Power Electron., vol. 25, no. 9, pp. 2420-2432, Sep. 2019.

5. C.-L. Chen, Y. Wang, J.-S. Lai, Y.-S. Lee, and D. Martin, "Design of parallel inverters for smooth mode transfer microgrid applications," IEEE Trans. Power Electron., vol. 25, no. 1, pp. 6-15, Jan. 2020

6. Kesavan, S., Saravana Kumar, E., Kumar, A., \& Vengatesan, K. (2019). An investigation on adaptive HTTP media streaming Quality-of-Experience (QoE) and agility using cloud media servicesInternational Journal of Computers and Applications, 1-14.

7. B. P. Mcgrath, D. G. Holmes, and J. J. H. Galloway, "Power converter line synchronization using a discrete Fourier transform (DFT) based on a variable sample rate," IEEE Trans. Power Electron., vol. 20, no. 4, pp. 877-884, Apr. 2018

8. F. Liu, Y. Zhou. S. Duan, J. Yin. B. Liu, and F. Liu, "Parameter design of a two-current-loop controller used in a grid-connected inverter system with LCL filter," IEEE Trans. Ind. Electron. , vol. 56, no. 11, pp. 4483-4491, Nov. 2019.

9. M. Liserre, R. Teodorescu, and F. Blaabjerg, "Stability of photovoltaic and wind turbine gridconnected inverters for a large set of grid impedance values," IEEE Trans. Power Electron., vol. 21, no. 1, pp. 263-272. Jan. 2020.

10. Kumar, A., Vengatesan, K., Rajesh, M., \& Singhal, A. (2019). Teaching literacy through animation \& multimediaInt. J. Innovative Technol. Exploring Eng, 8(5), 73-76

11. A. Micallef, M. Apap, C. Spiteri-Staines, J. M. Guerrero, and J. C. Vasquez, "Reactive power sharing and voltage harmonic distortion compensation of droop controlled single phase islanded microgrids," IEEE Trans. Smart Grid, vol. 5, no. 3, pp. 1149-1158, 2019. 